\title{
Motor Skills Performance of Children with Hearing Impairment using Different Modules and Physical Education Setting
}

\author{
Abdulrahman Nasser Alshahrany*1,HalijahBt Ibrahim ${ }^{1}$ \\ *1Physical Education, Faculty of Education, University of Bisha, Saudi Arabia. \\ ${ }^{1}$ Physical Education, Faculty of Social Sciences and Humanities, University Technology Malaysia, Malaysia.
}

Article History: Received:11 January 2021; Accepted: 27 February 2021; Published online: 5 April 2021

\begin{abstract}
Over recent decades, the common understanding of hearing impairment has improved. People are more concerned with hearing impairment and have come to a consensus that care and positivity must be addressed. Therefore, recent trends in children with hearing disabilities inclusion have started in regular schools. The holistic training program provides opportunities for everyday people to learn about their abilities and special skills. The teacher needs to take care of the locomotive and object control skills of the child through the development of necessarymotor skills to meet life requirements, such as walking, running, throwing, etc. The current study explores the ability of primary school children with hearing loss to incorporate an exergame to improve fundamental motor skills within an inclusive physical education classroom in Saudi Arabia. The study used a Qualitative Method and carried out a content analysis together with a Systematic Literature Review to understand the research carried out in this field. A detailed analysis was carried out of secondary data from articles indexed in Scopus and the websites of the scientific databases and other related documents in the field of study. This study would expand the research awareness related to the success of vital engine skills in elementary school children with hearing impairment through the use of an exergame in comprehensive physical education.
\end{abstract}

Keywords -Performance of Fundamental Motor Skills, Elementary schools in KSA, Hearing Impairment

\section{INTRODUCTION}

The human perception of the world is heavily dependent on the recognition and analysis of the details sensed through the five basic senses; sound, vision, scent, taste and touch. Every deficiency in one or more of these senses leads to some difficulties. The meaning of the hearing, the topic of discussion in this study, is one through which the sound is experienced and perceived as sensations by the brain. Hearing facilitates human communication through languages and provides the basis for understanding social behavioural, ultimately leading to environmental development irrespective of existing daily challenges [1],[2]. The condition of being unable to detect or sense sound is called surrender or loss of the hearing. There are about 360 million people worldwide living with, at least, one form of hearing impairment with 32 million of them children [3].

Children with impaired hearing have been shown to have difficulties for human development in terms of vocabulary, voice, emotional, cognitive and FMS, and early detection and early intervention has been vital to alleviating most of these issues for a better overall quality of life [3], [4]. Barker et al. [1], also noted that early developmental problems are a relatively stable risk factor for pupils with hearing impairments in certain aspects of life, such as poor academical performance, future behavioural problems and communication avoidance with hearing staff. FMS of hearing-impaired children has reported significant delays compared to their hearing pairs [4]. For children [6] [7] the creation of FMS is substantial as it forms the basis for a physically active lifestyle and their lifelong enjoyment and participation in sport. Contrary to this, lack of or insufficient engine skills may lead people to inactive behaviour and sedentary lifestyles, one of the reasons behind growing cases in recent years of overweight and obesity [8].

In conformity with the claim that a critical period to instil the object control and locomotor skills is in the early childhood and primary school stages due to their willingness to learn and implement instruction [9], the existing studies on FMS performance and development have primarily focused on children using school-based PE classes as a medium of FMS training. However, very few have focused on children with hearing impairment despite their inherent need for it.

An increasing trend in the education of children with disabilities and specifically those with hearing impairment is the concept of inclusion or mainstreaming or inclusive education. It entails teaching hearing-impaired children alongside their hearing peers in the same class within the same mainstream educational setting. It is expected that by so doing, most of the deficiencies as regards their language, social, academic and general societal perception of them 
will be improved[10]. Representative studies have shown positive feedback from parents and teachers on this initiative [10], [11]. However, when it comes to FMS related studies, only a preliminary survey ofGursel [12] has been carried out in an inclusive setting. It is, thus, pertinent to further investigate the performance of FMS in hearing-impaired children in an inclusive educational setup for a broader perspective of the approach.

The contribution of Video Games (VGs) amongst other technological advancements to the growing sedentarily in children and teenagers of this generation has attained an epidemic scale [13]. Given its captivating and motivating yet challenging nature, increasing attempts have been made to reduce the stationary quality of traditional VGs by incorporating a physical activity component to tackle some of its drawbacks [14]. Thus, Exergames, VGs, which adds a physical activity component to the otherwise stable VG environment, has been proposed a few decades ago. Representative studies have shown exergames are increasingly used in PE classes and has been incorporated into the PE curriculum of some public schools in the United States [14], [15]. In addition to its ability to improve physical fitness, motor skills, and is highly motivating for physical exercise, studies have also shown that exergamesare capably alleviating characteristic loneliness in challenged children through increased group participation via multiple players mode [16]. Exergames have also been reported amongst other technology-oriented interventional studies related to children with hearing impairment [17], [18]. However, the only related study to FMS development in hearing-impaired children is in [19], where the balance ability of adolescents with hearing impairments were tested after an exergame-based balance training. Finding reveals improved balance ability at post-test. An important future direction suggested by the authors is the need to investigate the effectiveness of this mode of balance training in multiple settings and populations.

Investigating the impact of interventions like FMS under varying populations gives a broader perspective of the study. It exposes the possibility of other confounding factors behind specific findings if it exists. Saudi Arabia. Hence, the establishment of initiatives like the Universal newborn hearing screening (UNHS), which ensures that every newborn is screened for the hearing problem in the first few weeks of their birth[5]. However, FMS related studies on children with hearing impairment still lackin this population. Although inclusive education exists for the hearing-impaired, it only happens during PE and Art classes and intervals between categories [20], [21]. Given the apparent lack of studies, the Saudi population of hearing-impaired children becomes an ideal one for this research.In essence, this study investigated the performance of FMS among Saudi Arabia elementary school childrenwith hearing impairment using technology-oriented interventions like exergames in an inclusive physical education classroom. By so doing, the study hopes to broaden on FMS of children with hearing impairment, especially in an inclusive educational setup and impact technology-driven approaches have on their locomotor and object control skills.

Fundamental Motor Skills (FMS), a combination of movement patterns of two or more body parts to form series of basic movements required for active participation in physical activities, is the foundation for a physically active lifestyle and life-long enjoyment of sporting activities [22]. Physically active children are less likely to be overweight and tend to enjoy sporting activities than less physically active ones who prefer a more sedentary lifestyle [8]. Children who have higher levels of physical activity have been reported to possess a better mastery of the fundamental movement/motor skills (FMS) [23]. Contrarily, those with a deficiency in FMS tend to suffer a delay in their gross motor development and prefer a less active lifestyle; an essential factor in the rising cases obesity among children (Salmon et al., 2008). Hence, it is necessary to impart such FMS to children in early childhood as it has been reported in the literature to also contribute to their social, physical and cognitive development [24].

Although the importance of FMS in child development cannot be overemphasised, specific disabilities like Hearing Impairment put children at higher risk of not acquiring the necessary skills for their healthy growth and independence. Hearing impairment, either congenital or acquired can range from mild, where there is a partial loss in the ability to listen to, to severe or profound, where there is total inability to understand or perceive sound. Representative studies have shown that children with hearing impairment suffer a significant delay in their gross motor skills compared to their hearing peers [4], [12]. Through early detection of hearing impairment and prompt medical intervention, inherent difficulties in speech, communication and delays in gross motor skills development can be alleviated; resulting in a more active lifestyle and lifelong enjoyment of their individual and social endeavours [25], [4]. Hence, pertinent literature on FMS development has mostly focused on children while leveraging school-based Physical Education (PE) classes as the primary medium of the intervention [26], [8], [27], [12]. 
While school-based interventions via PE classes have been the conventional media of training in FMS-related studies for children, the number of studies on FMS amongst children with hearing impairment is limited; confirming earlier studies highlighting the inadequacy of research studies on the development of FMS in children with hearing impairment [25]. Therefore, the need for more education on the performance of FMS among children with hearing impairment remains an open area; especially on populations where such studies have not been reported in the literature.

Individuals with hearing impairment also require special attention and education to adapt to life's needs and to live better in line with their skills and strength. Inclusion, therefore, is becoming more and more a standard model of joint education in the developed countries for students with disabilities and their normal peers in the same mainstream education environment [10]. Whilst critical from some areas has been faced with this idea, the literature reports on their benefits in promoting healthy interaction among hearing-impaired individuals and their peers, enhanced language and academic growth, and more substantive recognition and appreciation of persons with hearing impairments [20], [28]. Furthermore, a preliminary study on participation in PE has shown positive results in several areas of their physical and social growth on the FMS development of children with hearing impairment [12].

The use of electronic and digital technologies in the education of children has risen significantly in recent years, particularly children with hearing and hearing loss [17]. Some countries are making concerted efforts to introduce children with special needs into the digital world, particularly those with hearing impairment. It is expected that a range of technical opportunities will be used to improve health, education and other aspects of life [18], [17], [29], [30]. In comparison, technological progress also represents an important explanation for unhealthy behaviours given the time that children spend on on-screen screens [8], [16]. As childhood inactivity increases and obesity levels grow, attempts were made, using key technical elements such as video game (VGs) to increase the level of physical activity in adolescents, to reverse this negative trend [31].

Saudi Arabia has been shown as useful in the early detection of hearing impairment in children through recent research [5]. Studies of quality intervention research aimed at alleviating the developmental difficulties which are still scarce in Saudi Arabia for children with hearing impairment, especially those linked to FMS development or success among elementary school children. In Saudi Arabia, other remarkable work has centred on universal schooling about early detections of children with hearing impairment [5] to the point that it has an effect on their language development and the understanding of their parents, guardians and teachers [20], [32]. In comparison, Saudi Arabia has a primarily social inclusion; where students with hearing impairments learn, except PE, art classes and class periods, in classrooms independently from their regular peers within the same framework [21]. The current study explores the ability of primary school children with hearing loss to incorporate an exergame to improve fundamental motor skills within an inclusive physical education classroom in Saudi Arabia.

\section{MATERIALS AND METHODS}

The present study used a qualitative method and conducted a content analysis along with the systematic literature review to understand the research done in this field and to set the agenda of future research in this area.A secondary data collected from articles indexed inScopus and web of science databases and other related documents in the field ofthe studywas analyzed in details. A thorough literature review is very relevant before carrying out this rigorous research study. The evaluation took place in the following stages: (1) selection of parameters for inclusion and exclusion, (2) data sources and search strategy, (3) quality assessment, and (4) coding and processing of results. The corresponding sub-sections explain the details of these measures more clearly.

\section{Inclusion/Exclusion Criteria}

The papers have been reviewed, assessed and must conform to the criteria requirements of inclusion and exclusion - the inclusion criteria presented in Table 1. 
Table 1. Inclusion and Exclusion Criteria

\begin{tabular}{|l|l|}
\hline Inclusion Criteria & Exclusion Criteria \\
\hline $\begin{array}{l}\text { Should involve studies on } \\
\text { the Performance of }\end{array}$ & $\begin{array}{l}\text { Papers that are not involved } \\
\text { in on the Performance of }\end{array}$ \\
$\begin{array}{l}\text { Fundamental Motor Skills, } \\
\text { Elementary schools in KSA, } \\
\text { Hearing Impairment. }\end{array}$ & $\begin{array}{l}\text { Fundamental Motor Skills, } \\
\text { Elementary schools in } \\
\text { KSA, Hearing Impairment. }\end{array}$ \\
\hline $\begin{array}{l}\text { Should have been written in } \\
\text { English. }\end{array}$ & $\begin{array}{l}\text { Articles used in general } \\
\text { context for ads, but not in } \\
\text { the marketing and } \\
\text { advertising on social } \\
\text { media. }\end{array}$ \\
\hline & $\begin{array}{l}\text { Papers that use non-English } \\
\text { language. }\end{array}$ \\
\hline $\begin{array}{l}\text { Due to publishing between } \\
\text { 2015 and 2019 }\end{array}$ & \\
\hline
\end{tabular}

\section{Quality Assessment}

Another factor that can be used together with the inclusion and exclusion criterion is the content evaluation of the selected articles. There has been a developed performance assurance checklist of eight parameters to assess the quality of the studies that are held for more review $(\mathrm{N}=27)$. The study use quality assurance checklist. All questions are graded at a rate of three points with a rating of 1 point "Acceptable," 0 points "Not Acceptable" and 0.5 points "Partially Acceptable." Thus, the higher the overall rating received by this test, the higher the degree to which the problems from the analysis in this report will be dealt with. In this context, the quality assessment has correctly been performed for all tests, and all the studies are eligible to be further evaluated. The following is the checklist comprising eight criteria used to determine research quality: (1) Are the goals of the study clearly defined? (2) Were these goals accomplished in the study? (4) Is it evident what the study's context/discipline was? (5) Are the data collection techniques accurate enough? (6) Does the research show the reliability/validity of the measure? (7) Is there a good description of the statistical methods used to examine the data? (8) Are the findings applied to the literature? (9) Will the study help you understand or learn?

\section{Data coding and analysis}

The associated features of the research methodology include: (a) theoretical problems, (b) procedures, (c) country (d) discipline/context and (e) publishing year. During the data analysis phase, experiments that did not show explicitly the social media and foreign ads were omitted from the study. The theoretical problems are listed from the three theoretical bases. The network capability, transferability of images and personal extensibility are these theoretical foundations or perspectives.

\section{RESULTS}

The present study used a qualitative method and conducted a content analysis along with the systematic literature review to understand the research done in this field and to set the agenda of future research in this area.It entails the overview of hearing impairment, and assessment of published works on hearing impairment in Saudi Arabia. Fundamental Motor Skills (FMS) is also discussed vis-à-vis pertinent theories and review of important works on FMS generally and as it relates to Saudi Arabia. Also, the concept of inclusion as a form of education is briefly introduced and discussed in the context of Physical Education (PE). Representative studies as it relates inclusive education for children with hearing impairment in Saudi Arabia are also reviewed here. Finally, Technologyoriented PE is discussed with emphasis on exergames after which a summary of the literature review is presented.

\section{On Hearing Impairment}

One of the five basic sense organs of every human is the ear whose basic function is for hearing. In its basic form, the hear functions as a processor of sound waves through the collective operation of the three main sections; the outer (to capture sound waves), middle (turn sound waves into vibrations) and inner (generate nerve signals) ears. Damage to one or more parts of the hearing system may result total or some degree of hearing loss. Any degree of difficulty in hearing that impedes correct or optimal perception of sound in human is known as hearing impairment/loss. While this disability could range in its severity from mild, where there is partial loss in ability to 
hear, to severe or profound, where there is total inability to hear or perceive sound it can also be bilateral (both ears) or unilateral (one ear).

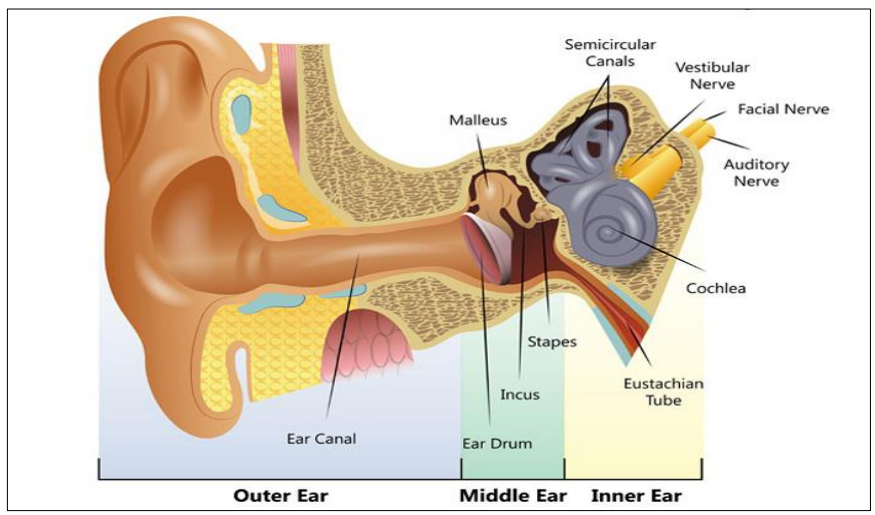

Fig. 1. The Human Ear

One of every human being's five essential sense organs is the ear of which the primary function is to hear. In its core type, the hearing acts as a sound wave processor by the combined activity of the three main sections: the outer (shock waves to be recorded), middle (sound waves to be vibrated) and inner (nerve signal generation). Damage to one or more areas of the auditory system may result in absolute or a certain hearing loss. Any type of hearing problems that hinder the right or adequate perception of the human sound is considered hearing impairment/loss. While this condition may range from moderate, partial hearing loss, extreme, or worse if there is full hearing or perceiving sound, it can also be bilateral (both ears) or unilateral (one ear).

Regardless of the cause, early detection is important to diagnose the degree of hearing loss and to support the patient in the therapy required to improve overall quality of life. Hopper [33] also provided a conductive, sensorineural, or mixed categorization of hearing loss. The loss of hearing is called conductive if the injury only affects the outside or muzzle ear. The use of hearing aids or other medical interventions can often be enough to restore normal hearing in this form of hearing loss. Nonetheless, there is variability or disturbances of sound frequencies or general hearing deficits with sensorineal form, due to damage to nerve fibers connected to the inner ear or other sensory problems, and these can or can not be resolved by specialized listening aids such as CI. The mixture of conductive as well as sensorineural hearing deficits is the mixed kind.

Worldwide, there are about 360 million individuals, 5 percent of whom are with one form or the other of hearing impairment. Since more than 11 percent of the world's population are children, early detection of any form of hearing loss or disability and intervention is necessary to rising the majority if not all of the hearing impaired challenges. Children with hearing loss / impairment ranging from mild to extreme are well known to suffer from speech disturbances and challenges with their socio-emotional and educational endeavours.

Representative studies have shown that FMS and child physical activity can be improved by extending the life of physical education [26]. In addition to the reduced risk of overweight and diabetes [8] strong motor skills are a vital factor for developing a desire for children to engage in physical activities and sports [34] significant motor problems with their ordinary peer [4]. Psychomotive delays are characteristic of children with hearing impairments, which may influence their object control and locomotive skills [35], [36]. Therefore, the increased demand for specialised care by increasing physical activity and the acquisition of motor skills for children with hearing disabilities to prevent isolation and sedentary lifestyle that have a lasting impact on their overall quality of life [37], [38].

\section{Hearing Impairment in Saudi}

All levels of education, including primary, secondary and high school, is free in Saudi Arabia [39]. However, notable government focus on special education through increased funding to specific areas like Hearing impairment, autism, physical disabilities, and intellectual disability began in the year 2000. The first known school for children with hearing impairment were two Al-Amal Institutes which were established in 1964 in Riyadh by the Ministry of Education; for both boys and girls, respectively [40]. This shows the long history of care Saudi Arabia has for 
children with physical impairment and correctly hearing impairment which has in recent years seen the establishment of initiatives like the Universal newborn hearing screening (UNHS)[5].

A report from the General Authority Statistics of Saudi Arabia (2018) estimates about $0.8 \%$ of the over 32 million Saudi Arabia populace to be living with one form of hearing impairment or another. Given the resulting possible adverse lifelong effect it may have on communication and the general quality of life, some developing countries like Saudi Arabia through the UNHS ensure hearing screening tests in the first few weeks of their birth of a newborn (Alyami, 2016). Prior to the establishment of these programs, mild hearing impairment are often rarely detected till a child begins school (Annual Report, king Abdulaziz Medical City, 2012). Besides, preschool hearing screening tests have been suggested to detect delayed-onset hearing impairment.

Early detection of hearing impairment and improved communication and language development are strongly associated [41]. Al-Rowaily et al., [42] in their research on the prevalence of hearing impairment among 2574 kindergarten and primary school children in Saudi Arabia reported that 1.75\% of these children have a hearing impairment. Their findings reveal conductive hearing impairment as the dominant form of hearing problem with otitis media with effusion being the leading cause. Other reported causes include wax and chronic otitis media, and traumatic perforated drum. About $16.2 \%$ of the reported cases suffer sensorineural hearing loss.

In a similar study byHumaid et al.[43] the prevalence of Otitis Media with effusion among school children (age = 612) in Saudi Arabia region of Qassim is reported to be 7.5\%. Family size of greater than 4, living in rural area, recurrent acute otitis media, mother's education below secondary school level, child age below 8 years are some of the risk factors highlighted for of Otitis Media with effusion. In addition, findings have shown that there are cultural, environmental and prenatal conditions that might increase the chance of hearing impairment in a new-born; especially the congenital form. One of such cultural reasons for congenital hearing loss in the Middle East where Saudi Arabi belongs is consanguineous marriages. Although, no representative study on its impact on hearing impairment have been carried in Saudi Arabia, the fact that the significant increase in risk of hearing loss and other congenital impairments with successive consanguineous marriages has been established in other studies[44].

Summarily, the Saudi Arabia government have been proactive in its care for the hearing-impaired children but the prevalence of hearing loss amongst school children is still reported in literature [43]. This means that special attention needs to be dedicated to factors that are known to affect their individual development and general quality of life in the long term. Studies have shown a significantly lesser motor skills - an important requirement for a physically active lifestyle- in hearing-impaired children relative to their normal peers. Children who are deficient in motor skills tend to be sedentary in nature and at risk of obesity; a rising trend in children [8]. It will be of great importance to examine fundamental motor skills performance amongst Saudi Arabia children with hearing impairment.

\section{Fundamental Movement System}

Healthy growth of children and their development are known to be positively associated with their level of physical activity (Janssen \& LeBlanc, 2010). Physically active children are less likely to be overweight, especially when their food intake is also adjusted, and more likely to enjoy sporting activities than less physically active ones who adopt a more sedentary lifestyle. While physical activity benefits the body in burning excess body fats, it also serves as a primary means of developing fundamental movement/motor skills (FMS); a combination of movement patterns of two of more body parts to form series of basic movements required for active participations in many physical activities [22].

FMS generally fall into three categories; locomotor, object control or manipulation and stability skills. Locomotor skills involve such skills as running,galloping, skipping, hopping and jumping amongst others while object control skills include catching, kicking, striking, rolling, throwing etc. Stability skills, on the other hand, include balancing, twisting etc.[46]. Clark [47] has defined FMS as the basic abilities and skills a child requires to take and organize a series of movements needed in sports and other activities using the necessary body parts. Studies have shown that basic motor skills are instruments through which children interact with the environment around them. The motor skills a child requires to meet his or her daily needs in life without any difficulties are walking, running, jumping, throwing, etc. FMS can also be grouped into the structured and unstructured motor. 
The structured motor includes specific skills and patterns to achieve a specific goal. This movement is characterized by accuracy of movement and includes skills such as: walking, jumping, throwing, hitting the ball and others that are performed by the child in accordance with the specific combination and correct response. Unstructured motor, on the other hand, deals with the control of body movements. The aim is to develop the understanding of the child and efficiency of the evolution of the body anywhere. The child basically focuses on exploration, innovation and replication. Likewise, this movement is characterized by a variety of reactions which includes expressive, such as movements performed by children due to joy or anger, and analytical movements such asmovements that rely on simulating movements of animals and others [45].

Children with low gross motor skills are less healthy and tend to suffer from low level of self-efficacy in physical activity.Children who have higher levels of physical activity have been reported to have a mastery of the object control and locomotor skills [23]. This is because FMS is the basis on which skills and movements involved in many physical and sporting activities are built. As such children with deficiency FMS tend to suffer delay in their gross motor development and do not enjoy participation in sports because each sport-specific skill often a combination of one or more motor skills e.g. in basketball there is repeated combination of running, galloping, jumping, catching and throwing. Hence, being a set of basic movement skills on which many physical activities are built, FMS should be developed and learnt through well-monitored practice and quality instruction [48].

Gross motor skill acquisition is significant during the early life of children as findings have shown its contribution to their social, physical and cognitive development [24]. Although obvious limitations exist in the enjoyment of exercise and qualitative aspects of motor skill development a child can achieve, the early childhood is an essential period for maintaining and improving the object control and locomotor skills, academic attainment and reaction time [49]. Thus, Willgoose[6] believes that the FMS should be introduced to children between the ages of 1 to 12 years. This falls within the primary school level which has been suggested by other researchers as being critical for FMS development because children are young and more willing to implement the object control and locomotor skills programs at this stage [9].

Furthermore, training in the early and middle childhood phase should be carried out by a teacher who focuses extensively on the development of basic or fundamental movements in the child and the best ways to apply the learnt skills. One may argue that the child can spontaneously get the basic moves through his or her innate abilities, but the invaluable role of the teacher in encouraging and stimulating the self-discovery in relation to the surrounding environment cannot be overemphasised. It is important to take a practical interest in motor learning which leads to the acquisition of basic motor skills in children since the development of the FMS has been described as the foundation for child development.

\section{Studies on Fundamental Motor Skills Development}

This paper presents studies conducted on fundamental motor skills development. There were eight studies synthesized. As shown in Table 2. At present, Van Beurden [26] in their research, focused on the impact of interventions through physical education lessons to improve child fundamental motor skills and physical activity in Australia. Pre-post observation surveys were also used. Results show that intervention programs improved fundamental motor skills and physical activity of children through physical education lessons. In like manner, Salmon et al. [8] evaluated the effectiveness of an intervention in improving the object control \&locomotor skills by reducing sitting watching TV, increase participation and physical activities among children. Findings show sex and age had a significant effect from baseline to post-intervention. Accordingly, Akbari et al. [48] studied the impact of traditional games on the object control and locomotor skills development. Findings show a better development in object control \&locomotor skills of the first group.Ericsson [34] studied the effect of an extension of physical activity and motor training on motor skills and marks of children in school subjects in Sweden over a period of nine years. The intervention group had significantly better motor skills through balance and coordination than the control group.

Table 2. Summary of Pertinent Research on Motor Skills Development

\begin{tabular}{|c|c|c|c|l|}
\hline Study & Sample; Age; Location & $\begin{array}{c}\text { Design and } \\
\text { Intervention Type }\end{array}$ & $\begin{array}{l}\text { Hearing } \\
\text { Impairment? }\end{array}$ & $\begin{array}{l}\text { FMS } \\
\text { measure }\end{array}$ \\
\hline $\begin{array}{c}\text { Beurden et } \\
\text { al., (2003) }\end{array}$ & $\begin{array}{c}\mathrm{N}=1045 \text { (male= 53\%, female=47\%); 7-10 } \\
\text { yrs.; New South Wales Australia }\end{array}$ & $\begin{array}{c}\text { quasi-experimental; } \\
\text { School-based }\end{array}$ & $\begin{array}{l}\text { No } \\
\text { Pre-post } \\
\text { observational } \\
\text { surveys }\end{array}$ \\
\hline
\end{tabular}


Motor Skills Performance of Children with Hearing Impairment using Different Modules and Physical Education Setting

\begin{tabular}{|c|c|c|c|c|}
\hline $\begin{array}{l}\text { Salmon et } \\
\text { al., (2008) }\end{array}$ & $\begin{array}{c}\mathrm{N}=311(\text { male }=49 \%,) ; 10 \mathrm{yr} 8 \mathrm{mnths} \text { average; } \\
\text { Melbourne Australia }\end{array}$ & $\begin{array}{l}\text { Group-randomized } \\
\text { controlled trial; } \\
\text { School-based }\end{array}$ & No & $\begin{array}{l}\text { Others not } \\
\text { clearly stated }\end{array}$ \\
\hline $\begin{array}{l}\text { Akbari et al., } \\
\quad(2009)\end{array}$ & $\begin{array}{c}\mathrm{N}=40(\text { male }=100 \%) ; 7-9 \text { years; Semnan, } \\
\text { Iran }\end{array}$ & $\begin{array}{l}\text { quasi- } \\
\text { experimental design; } \\
\text { School-based }\end{array}$ & No & $\begin{array}{l}\text { Test of Gross } \\
\text { Motor } \\
\text { Development } \\
\text { (TGMD-2) }\end{array}$ \\
\hline $\begin{array}{l}\text { (Ericsson, } \\
\text { 2011) }\end{array}$ & $\begin{array}{c}\mathrm{N}=263 \text { (male }=49 \% \text {, girls }=51 \% \\
\text { intervention=161, control }=102 \\
\text { baseline=7yr, follow-up= } 15 \mathrm{yrs} ; \text { Sweden }\end{array}$ & $\begin{array}{l}\text { longitudinal study; } \\
\text { school-based }\end{array}$ & No & $\begin{array}{l}\text { MUGI } \\
\text { checklists }\end{array}$ \\
\hline $\begin{array}{l}\text { (Sabah, } \\
2011)\end{array}$ & $\begin{array}{c}\mathrm{N}=40(\text { girls }=100 \%, \text { intervention }=20 \\
\text { control= 20); } 9 \text { yrs average; Ahwaz City, } \\
\text { Iran }\end{array}$ & $\begin{array}{l}\text { semi-experimental; } \\
\text { school-based }\end{array}$ & No & $\begin{array}{l}\text { Test of Gross } \\
\text { Motor } \\
\text { Development } \\
\text { (TGMD-2) }\end{array}$ \\
\hline $\begin{array}{l}\text { (Araujo et } \\
\text { al., 2012) }\end{array}$ & $\begin{array}{c}\mathrm{N}=41 ; \text { intervention }=9.6 \mathrm{yrs} \text {, control }=9.5 \\
\text { yrs. average; Sao Paulo city, Brazil }\end{array}$ & ; school-based & No & TGMD-2 \\
\hline $\begin{array}{l}\text { (Sirinkan } \\
\text { 2014) }\end{array}$ & $\mathrm{N}=24 ; 9-12$ yrs.; Turkey & $\begin{array}{l}\text { Pre-posttest design; } \\
\text { school-based }\end{array}$ & Yes & $\begin{array}{l}\text { Others Not } \\
\text { stated }\end{array}$ \\
\hline $\begin{array}{c}\text { (Gursel } \\
2014)\end{array}$ & $\begin{array}{c}\mathrm{N}=18 \text { (7 hearing impaired and } 11 \text { normal }) ; \\
60-70 \text { months.; Turkey }\end{array}$ & $\begin{array}{l}\text { quasi experimental } \\
\text { design; school-based }\end{array}$ & Yes & TGMD-2 \\
\hline
\end{tabular}

Experimental findings show significant statistical differences between experimental and control groups motor skills, manipulation skills and overall motor development; favouring the experimental group in all cases. Selected exercises were also found to bring more progress in girls' motor development and specifically impacted their motor development in subjects in third grade of elementary school. A positive association is also reported to exist between motor skills development and physical activity. Consequently,

Araujo et al. [27] conducted a study which investigated the contribution of PE classes to the development of basic motor skills of children in anelementary school in Sao Paulo city. The control group consisted of 19 students with average age of 9.5 years while experimental group comprised of 22 students with average age 9.6years. Result shows that the experimental group has higher scores compared to their control counterpart in the locomotor test while both groups had similar scores in the object control subtest. This work further corroborates the findings [50] where the effectiveness of an intervention program among school children was examined through expanded physical education lessons. In addition to an improved BMI, a more positive physical index was also notable in the intervention group than the control.

For SIrinkan and Sirinkan [51],it was investigated that contribution of educational games to students with hearing impairment through football adapted it to the development of their physical and technical skills show significant development in football basic techniques and physical characteristics of children with hearing disability after the training. Gursel [12] also conducted a study to determine the impact of an inclusive intervention program on motor skill development for a total of 18 children, aged 60-70 months. Seven of the children have hearing impairment while the remaining 11 are normal; all at a preschool in Turkey. The intervention programs which lasted for six weeks featured (pre-post) quasi-experimental design and Test of Gross Motor Development (TGMD-2) was used to measure skills like throwing, kicking, dribbling, catching, rolling, striking, sliding, jumping, leaping, hopping, galloping and running. Findings show that children with hearing impairment had a delay in development during pretest. However, after the intervention program development was noticedin their fundamental motor skills. A notable difference was said to happen in catching and striking ability to hear children for pre and post-test.

An overarching view of reviewed literature on FMS development, as summarized in Table 1, reveals that majority of studies on FMS development and performance have focused on children; a few of which deals with those children with hearing impairment. Thus, confirming earlier studies indicating the inadequacy of research on the development of FMS in children with hearing impairment [25]. Although there have been arguments in favour of the potential presence of other confounding factors behind delays in motor skills of hearing-impaired children, children with hearing impairment typically suffer significant motor development in comparison to their normal peers [4]. Hence, given the possible influence of environmental factors, it is important to explore the performance of FMS among children with hearing impairment in different settings; especially in other places where such studies are lacking. 
In addition, a notable trend in the published articles lies in the fact that the majority of the intervention type has been school-based predominantly via physical education (PE) classes and organized sports. This corroborates the already established notion that expertise FMS can best be attained over time through instruction, encouragement and practice, which is particularly integral in PE [22]. Thus, corroborating FMS competency as a core goal of elementary PE in developed countries like the US (National Association for Sport, \& Physical Education, 1995).

\section{Fundamental Motor Skills amongst Elementary School children in Saudi Arabia}

Representative studies have demonstrated Saudi Arabia as a tolerant country in the early diagnosis of childhood hearing loss [5]. Al-Rowaily et al. [42] estimate that Saudi pre-school children have around 1,75 percent of hearing impairment, while effusion otitis media are reported to be the leading cause. Although the detection of hearing impairment is an essential first step towards access to high-quality interventions, it itself does not ensure the eradication of potential lifelong communication deficiencies, social-emotional problems and general quality of life. Rather, the beginning of the action is the most important thing; the sooner, the better. Quality interventional studies aimed at reducing the developmental difficulties facing children with hearing disability in Saudi Arabia continue to be scanty; particularly those linked to FMS growth or success among elementary school children. Many prominent initiatives in Saudi Arabia have focused not only on early intervention program work for children with hearing loss in holistic schooling for them in terms of its effect on the language learning of children and teachers ' views of them. Therefore, more work is required in order to explore FMS amongst Saudi girls.

\section{Mainstreaming (Inclusion) Education}

The model of jointly educating students regardless of the disability in some of them has been described with different terms like mainstreaming, integration and inclusion [52]. These terms are thus used interchangeably in this research. Inclusion is simply the process of removing children with special needs from the isolation of special education setting in order to jointly educate them with their normal peers in the same classroom [53]. Alkhashrami[54] pointed out that children with special needs should be exposed to inclusion learning to be active in a natural environment with their normal peers. Furthermore, Alshaks\&Damatti[55] also suggested that the correct meaning of the concept of inclusion is to render services to children in need of special education through regular classes with their normal peers rather than isolating them. From a social perspective, Slee, [56] defined inclusion as a sociological term typically used to refer to an inclusive society in which all individuals especially children with special needs are valued and have important roles to play; highlighting that through inclusive schools, children with special educational needs can relate with their normal peers freely.

Although there has been variation in the various definitions of inclusion, a common theme across them is the inclusion of children with some form of developmental disabilities in mainstream educational settings. Integrating students with special education needs into the inclusive educational classroom allows them to interact and establish friendship naturally with those without disabilities [39]. Promoting social inclusion of students with special educational needs with their normal peers decreases the negative stigmatization that students with disability are often confronted [57]. While several studies have been published in favour of inclusion education for children with special needs [58] few works have also hinted that many children with special educational needs are more comfortable with their peers who have similar challenges, interests and disabilities [59].

\section{Inclusive education for children with hearing impairment}

The inclusion of hearing-impaired students in mainstream schooling is increasingly becoming a norm in the developed and European countries. Credits to international endorsement via legislations-like Americans with Disabilities Act (ADA) (1990), Disabled Care System in Saudi Arabia No/37 (12/20/2000), No Child Left Behind (NCLB) Act (2001) and Individuals with Disabilities Education Act (IDEA) (1997)-and improved research funding which has brought about technological advancement in hear implants like cochlear implant (CI). For example, it has become customary for deaf children in Europe to receive CI before the age of 3; thereby facilitating easier oral language learning and making their education in inclusive setting fun [10].

Although not the same can be said of many developing and underdeveloped nations, representative studies have shown that even with CI children with hearing impairment are behind their hearing peers when it comes to their motor skills. Schlumberger et al., [60] in their studies reported that normal motor skills performance cannot be expected from hearing-impared children despite CI implant because such children still show delay in their motor and 
balance development relative to their hearing peers. For such children, physical education in an inclusive educational setting might be a viable way for FMS development opportunities as suggested [61].

While several policies and Acts have been promulgated in support of inclusion, inclusive education has not generally been accepted from all quarters. Reseachers in support of it believe that most developmental delays that hearing impaired student are known with are, to some extent, due to their segregation from their hearing peers [28]. They aregue that inclusion engenders healthy cooperation between students irrespective of their disability and enables the hearing impaired to immitate their hearing peers; especially in language development and other educational endeavours[20]. In addition, the societal perception of these class of children will naturally improve and raise their sense of belonging as important members of the the society they belong. This in turn leads to a society with respect for indidual difference ans strang awareness of individual difference.

On the contrary, those who oppose inclusive education for hearing impaired children believe it limits their chances of achieving good communication and leads to the deprivation of the required attention for their individual education which exposes them to failure in their education; particularly when equally assessed as their hearing peers. In fact, traditional school teachers are not qualified to educate students with hearing impairment; a disparity that may result in children with hearing disability lacking essential concepts that are thought about in class. While studies have shown that some students with hearing loss favor inclusive education [58] it is likely that a deaf student who interacts with sign language may feel isolated in a school where signing culture is not available. Therefore, to achieve its ultimate aim for inclusive education, as a laudable move, the requisite support resources should be placed in place for teachers and students alike to ensure its ever-present success.

The perculiarity of hearing loss as an invisible form makes it much worse as the instructor may intentionally conceal his or her feelings or go completely unnoticed by the struggling student. Therefore, in order to excel academically, hearing impaired students in comprehensive schools need some individual changes and some additional support services. Morningstar et al. [62] provided specifics of some of the required support services. It is critical for intimate teachers to ensure the success of children with hearing disability and their peers in the inclusive educational setting on the culture of the hearing impaired children, their communication needs and the required modifications to the teaching methods.

A pertinent study on support for hearing impaired student is the one reported [10] on students with hearing impairment who attended regular schools in Finland. The aim of the study was to investigate how teachers support these students in an inclusive setting. There were about 109 teachers, with both closed and open-ended questions, who taught students with hearing impairment in mainstream education at primary schools. According to the result, the main support offered by the teachers were mostly pedagogical and technical support. Findings also showed $48 \%$ of the teachers gave no support while most of the teachers consider the inclusive setting a success.Similarly, the impact of the inclusive intervention on the FMS performance of children with a hearing impairment has been studied. Notable is the one reported byGursel [12] Although limited in the number of samples and duration of study, a general improvement in FMS of children with hearing impairment was declared and the hearing samples.

\section{Inclusive physical education for children with Hearing Impairment}

Inclusive physical education as one that provides opportunities for all students regardless of their disability, to participate in physical education lessons [7] collectively. Integrated physical education emphasizes the right of all students to participate in any sporting or physical activity alongside their healthy peers irrespective of their disability. Hence, physical education programs in the inclusive setting tend to be slow yet steady because it caters for the need of all; both the disabled and typical peers.

It has been shown in earlier sections that physical education is the primary medium for school-based interventional studies on FMS development of elementary school children with hearing impairment. Representative studies have shown that the deficiencies inactivity and basic motor skill levels of children with hearing impairment in comparison to their typical peers can be alleviated through expanded physical education lessons [4]. Thus, it is essential that hearing-impaired children are given equal opportunities as their hearing peers in an inclusive physical education class.Furthermore, it is necessary for the PE teacher to understand that different communication strategies can be effectively used in the inclusive setting, and this could vary as the number of students. Therefore, the PE tutor should study each individual and identify the most effective communication strategies that soothe him or her best. A 
total communication approach which incorporates every available communication means possible has been suggested due to its success[63]. The tutor should not hesitate to give the hearing-impaired student full attention if he or she does not seem to understand how to carry out certain activities even after several attempts have been made. Likewise, the hearing-impaired students should be allowed at least one additional trial to ensure that they understand what is expected of them during the evaluation. They should also be given the opportunity to experience leadership either through team captainship or activity leaders to further increase their sense of belonging.

\section{Studies on inclusive education for children with hearing impairment in Saudi Arabia}

Almousa, [21] divided educational integration in Saudi Arabia into two methods namely Partial integration and total integration. Partial integration method is one in which children with special needs undertake their educational needs by attending special classes in the regular public schools where they are opportune to communicate with their normal peers during extracurricular and other activities. On the other hand, total integration method permits children with special needs to receive their institutional care with general education students and provide a variety of modern educational methods like source room programs, special education programs and mentor counsellor programs. Although the inclusion of hearing-impaired students with their hearing peers in conventional public schools in Saudi Arabia has started since the year 1990, the preponderant form of composition is largely social; where, except PE and Art classes and intervals between classes, the students with hearing impairment study in separate classes from their normal peers within the same school premise. The Saudi Ministry of Education hoped that this will at least bridge the communication gap between them and their hearing peers and further bring about an overall improved academic performance [20], [21].

Alkhateeb, Hadidi and Alkhateeb [11]conducted a study which involves an analysis of published articles on the inclusion of children with developmental disabilities in Arab countriesfrom 1990 to 2014. The study reviewed and analysed a total of 42 studies related to the addition of children with developmental disabilities in these countries; more than two of which came from each of Emirates, Saudi Arabia and Jordan. Many of these studies were conducted in the last eight years. A couple of them that relate to the inclusion of hearing-impaired students in Saudi Arabia are discussed in the following paragraphs. Share [20] conducted a study to examine the effect of addition on the language development of students with hearing impairment from the perspectives of teachers and parents. Teachers' assessment was high in respective language scores while parent's estimates showed no statistically significant difference between students with hearing impairment and their hearing peers at the inclusive schools.In another study that focuses on attitudes and perception towards inclusion, the view and knowledge of teachers and administrators towards children with hearing impairment in an inclusive setting in Saudi Arabia showed that attitudes towards the hearing-impaired children in mainstream schools were mostly negative [54].

Summarily, the lack of studies on other important aspects of inclusive education for children with hearing impairment in Saudi Arabia, such FMS development, is revealed from the quantity and focus of pertinent literature. Thus, stressing the need for more studies to be conducted in this open area of research.

\section{Technology-Oriented Interventions and Digital Culture Physical Education}

Digital Technology (DT) is a generic term that encompasses hardware or software-based products or solutions. The 21 st century is characterized by the ubiquitous use of DT in virtually every facet of human endeavor. Driven by the internet and technological advancement that has resulted in miniaturization of computer products, an entire digital culture where people, irrespective of their ages, increasingly interact with screen devices by watching television, playing video games (VGs) etc. has attained an unprecedented scale[16]. Advancement in technology has contributed greatly to inactive lifestyle in people of this generation, especially children, in recent decades. In fact, studies have linked inactivity in children to the amount of time spent on onscreen behavior which also serves as a major contributor to obesity and overweight in children [8], [16]. In contrast to the daily recommendation of a maximum of 2 hour in screen activities by health authorities [64], the only activity children spend more time doing besides playing VGs, watching television and using smartphones is sleeping [13]. Thus, as inactivity in children rise and the rate of obesity continue to soar, attempts have been made to reverse this negative trend by using key technological items like VGs to increase the level of physical activity in children [14]. Given the sedentary nature and time spent playing VGs, it is logical to associate increased physical activity component with it to tackle some of 
the health risks of inactivity in children. Hence, Exergames, VGs which adds a physical activity component to the otherwise stationary VG environment, have been proposed in recent decades.

\section{CONCLUSION}

The analysis includes a variety of papers on the performance of fundamental motor skills among elementary school children with hearing impairment. Rh research found that few studies focus solely on children with hearing loss. More studies on FMS is therefore required in children with hearing loss. Furthermore, all these experiments were carried out in a school-based, but non-inclusive, learning setting amid growing pressure for children with disabilities to be taught alongside their typical peers in the same educational set-up. Therefore, the latest study investigates the success of FMS in school kids with hearing difficulties in an inclusive PE classroom in Saudi Arabia; a nation without developing FMS studies despite any type of hearing loss identified by about $0.8 \%$ of its population. In PE schools, the use of technology-oriented approaches is increasing. Exergames, VG's which require sensor technology for motion or body movement to monitor characters and actions on the screen, have shown that students have been inspired to be more physically active, to increase their performance and to minimize seclusion in PE classes. Although a previous study documented comparable improvements in juggling skills between students with hearing loss who played exergames and those who practised in conventional PE methods, the locomotive and control aspect of FMS must also be explored.

\section{REFERENCES}

[1] Barker DH, Quittner AL, Fink NE, Eisenberg LS, Tobey EA, Niparko JK, CDaCI Investigative Team. Predicting behavior problems in deaf and hearing children: The influences of language, attention, and parentchild communication. Development and psychopathology. 2009 May;21(2):373-92.

[2] Patel H, Malawade M, Butte-Patil S, Khairnar P, Gawade S. Comparison of balance in children with and without hearing impairment. Int J Healthcare Biomed Res. 2017 Jan;5(5):19-27.

[3] World Health Organization. Global hepatitis report 2017. World Health Organization; 2017.

[4] Hartman E, Houwen S, Visscher C. Motor skill performance and sports participation in deaf elementary school children. Adapted Physical Activity Quarterly. 2011 Apr 1;28(2):132-45.

[5] Alyami H, Soer M, Swanepoel A, Pottas L. Deaf or hard of hearing children in Saudi Arabia: Status of early intervention services. International journal of pediatric otorhinolaryngology. $2016 \mathrm{Jul}$ 1;86:142-9.

[6] Willgoose CE. The curriculum in physical education.2005

[7] Almatar, A.. Special physical education for the disabled. Cultural Series of the Saudi Physical Education Federation, 5.2005

[8] Salmon J, Ball K, Hume C, Booth M, Crawford D. Outcomes of a group-randomized trial to prevent excess weight gain, reduce screen behaviours and promote physical activity in 10-year-old children: switch-play. International journal of obesity. $2008 \mathrm{Apr} ; 32(4): 601-12$.

[9] Hardy LL, King L, Farrell L, Macniven R, Howlett S. Fundamental movement skills among Australian preschool children. Journal of science and medicine in sport. 2010 Sep 1;13(5):503-8.

[10] Takala M, Sume H. Hearing-impaired pupils in mainstream education in Finland: Teachers' experiences of inclusion and support. European Journal of Special Needs Education. 2018 Jan 1;33(1):134-47.

[11] Alkhateeb JM, Hadidi MS, Alkhateeb AJ. Inclusion of children with developmental disabilities in Arab countries: A review of the research literature from 1990 to 2014. Research in developmental disabilities. 2016 Feb 1;49:60-75.

[12] Gursel F. Inclusive intervention to enhance the fundamental movement skills of children without hearing: a preliminary study. Perceptual and motor skills. 2014 Feb;118(1):304-15.

[13] Rosenberg S. Cell phones and children: Follow the precautionary road. Pediatric nursing. 2013 Mar 1;39(2):65.

[14] Staiano AE, Calvert SL. Exergames for physical education courses: Physical, social, and cognitive benefits. Child development perspectives. 2011 Jun;5(2):93-8.

[15] Lieberman DA. What can we learn from playing interactive games?.

[16] Vaghetti CA, Monteiro-Junior RS, Finco MD, Reategui E, da Costa Botelho SS. Exergames experience in physical education: A review. Physical Culture and Sport. Studies and Research. 2018 Jun 1;78(1):23-32.

[17] Turkestani MH. The Effect of iPad on School Preparedness among Preschool Children with HearingImpairments. International Education Studies. 2015;8(11):50-62.

[18] Havenga E, Swanepoel DW, Le Roux T, Schmid B. Tele-intervention for children with hearing loss: A comparative pilot study. Journal of telemedicine and telecare. 2017 Jan;23(1):116-25. 
[19] Vernadakis N, Papastergiou M, Giannousi M, Panagiotis A. The effect of an exergame-based intervention on balance ability on deaf adolescents. Sport Science. 2018;11:36-41.

[20] Shaira M. Effects of inclusion on language development in hearing-impaired students in Jeddah schools: Perspectives of teachers and parents. Life Science Journal. 2013;10(2):2374-83.

[21] Almousa, N.. Integrating children with special needs into general education - Educational vision, Riyadh.2004

[22] Gallahue DL, Donnelly FC. Developmental physical education for all children. Human Kinetics; 2007.

[23] Fisher AB, Reilly JJ, Kelly LA, Montgomery CO, Williamson AV, Paton JY, Grant ST. Fundamental movement skills and habitual physical activity in young children. Medicine \& Science in Sports \& Exercise. 2005 Apr 1;37(4):684-8.

[24] Lubans DR, Morgan PJ, Cliff DP, Barnett LM, Okely AD. Fundamental movement skills in children and adolescents. Sports medicine. 2010 Dec 1;40(12):1019-35.

[25] Rajendran V, Roy FG. An overview of motor skill performance and balance in hearing impaired children. Italian journal of pediatrics. 2011 Dec 1;37(1):33.

[26] van Beurden E, Barnett LM, Zask A, Dietrich UC, Brooks LO, Beard J. Can we skill and activate children through primary school physical education lessons?"Move it Groove it" - a collaborative health promotion intervention. Preventive medicine. 2003 Apr 1;36(4):493-501.

[27] Araujo, M. P. D., Barela, J. A., Celestino, M. L., \&Barela, A. M. F.. Contribution of different contents of physical education classes in elementary school I for the development of basic motor skills. RevistaBrasileira de Medicina do Esporte, 18(3), 153-157.2012.

[28] Shaira M. Effects of inclusion on language development in hearing-impaired students in Jeddah schools: Perspectives of teachers and parents. Life Science Journal. 2013;10(2):2374-83.

[29] FernáNdez-LóPez Á, RodríGuez-FóRtiz MJ, RodríGuez-Almendros ML, MartíNez-Segura MJ. Mobile learning technology based on iOS devices to support students with special education needs. Computers \& Education. 2013 Feb 1;61:77-90.

[30] Angkananon K, Wald M, Gilbert L. Technology enhanced interaction framework and method for accessibility in Thai museums. In2015 3rd International Conference on Information and Communication Technology (ICoICT) 2015 May 27 (pp. 316-321). IEEE.

[31] Staiano AE, Abraham AA, Calvert SL. Adolescent exergame play for weight loss and psychosocial improvement: a controlled physical activity intervention. Obesity. 2013 Mar;21(3):598-601.

[32] Alquraini TA. Factors related to teachers' attitudes towards the inclusive education of students with severe intellectual disabilities in Riyadh, Saudi. Journal of Research in Special Educational Needs. 2012 Jul;12(3):170-82.

[33] Hopper C. Physical activity and the deaf community. NCPAD Web site. Retrieved October. 2007;11:2012.

[34] Ericsson I. Effects of increased physical activity on motor skills and marks in physical education: an intervention study in school years 1 through 9 in Sweden. Physical Education \& Sport Pedagogy. 2011 Jul $1 ; 16(3): 313-29$.

[35] Gheysen F, Loots G, Van Waelvelde H. Motor development of deaf children with and without cochlear implants. Journal of Deaf Studies and Deaf Education. 2008 Mar 1;13(2):215-24.

[36] Rajendran V, Roy FG, Jeevanantham D. A preliminary randomized controlled study on the effectiveness of vestibular-specific neuromuscular training in children with hearing impairment. Clinical rehabilitation. 2013 May;27(5):459-67.

[37] Pfammatter A, Spring B, Saligram N, Davé R, Gowda A, Blais L, Arora M, Ranjani H, Ganda O, Hedeker D, Reddy S. mHealth intervention to improve diabetes risk behaviors in India: a prospective, parallel group cohort study. Journal of medical Internet research. 2016;18(8):e207.

[38] Müller AM, Alley S, Schoeppe S, Vandelanotte C. The effectiveness of e-\&mHealth interventions to promote physical activity and healthy diets in developing countries: a systematic review. International Journal of Behavioral Nutrition and Physical Activity. 2016 Dec;13(1):109.

[39] Alqahtani M. Teacher perspectives on full inclusion of students with learning disabilities in Saudi Arabia high schools (Doctoral dissertation, Indiana State University).

[40] Aldabas RA. Special education in Saudi Arabia: History and areas for reform. Creative Education. 2015;6(11):1158.

[41] Korver AM, Smith RJ, Van Camp G, Schleiss MR, Bitner-Glindzicz MA, Lustig LR, Usami SI, Boudewyns AN. Congenital hearing loss. Nature reviews Disease primers. 2017 Jan 12;3(1):1-7.

[42] Al-Rowaily MA, AlFayez AI, AlJomiey MS, AlBadr AM, Abolfotouh MA. Hearing impairments among Saudi preschool children. International journal of pediatric otorhinolaryngology. 2012 Nov 1;76(11):1674-7. 
[43] Humaid AH, Abou-halawa SA, Masood KA, Nuha AH, Al Duways Ali Saleh AM. Prevalence and risk factors of Otitis Media with effusion in school children in Qassim Region of Saudi Arabia. International journal of health sciences. 2014 Oct;8(4):325.

[44] Zakzouk S. Consanguinity and hearing impairment in developing countries: a custom to be discouraged. The Journal of Laryngology \& Otology. 2002 Oct;116(10):811-6.

[45] Ratib \& Alkholi. Physical Education School - a teacher teacher of the classroom and student practical education, Dar Alfikr, Cairo.1998

[46] Gallahue DL, Ozmun JC, Goodway J. Motor development: a theoretical model. Understanding motor development: infants, children, adolescents, adults. Boston: McGraw-Hill Interamericana. 2006:46-63.

[47] Clark JE. From the beginning: a developmental perspective on movement and mobility. Quest. 2005 Feb 1;57(1):37-45.

[48] Akbari, H., Abdoli, B., Shafizadeh, M., Khalaji, H., Hajihosseini, S., \&Ziaee, V. The effect of traditional games in fundamental motor skill development in 7-9 year-old boys. Iranian Journal of Pediatrics, 2009. 19(2), 123-129.

[49] Myer GD, Faigenbaum AD, Edwards NM, Clark JF, Best TM, Sallis RE. Sixty minutes of what? A developing brain perspective for activating children with an integrative exercise approach. British journal of sports medicine. 2015 Dec 1;49(23):1510-6.

[50] Sollerhed AC, Ejlertsson G. Physical benefits of expanded physical education in primary school: findings from a 3-year intervention study in Sweden. Scandinavian journal of medicine \& science in sports. 2008 Feb;18(1):102-7.

[51] Erciş, S., Şirinkan, A. and Şirinkan, Ş.Ö., . Research of Contribution of Educational Games Aimed for Football and Adapted to Hearing Impaired Students to Their Physical and Technical. International Journal of New Trends in Arts, Sports \&ScienceEducation, 2015 Jan 1;3(4).

[52] Cordente-Mesas D, González-Víllora S, Block ME, Contreras-Jordán OR. Structure, validity and reliability of the Children's Attitudes Towards Integrated Physical Education-Spanish version (CAIPE-SP). European Journal of Adapted Physical Activity. 2016 Jul 1;9(2).

[53] Alshakes, A.. Astudy of the integration requirements of the disabled in education and Arab society. , 1987.21, pp.189-213.

[54] Alkhashrami, S.. School for All - Integration of children with special needs into regular schools, Riyadah.2000

[55] Alshakes, A.; Damatti, A.. Dictionary of special education and rehabilitation of the ordinary. In: Khuraiji Publishing House, Riyadah.1994

[56] Slee R. The irregular school: Exclusion, schooling and inclusive education. Taylor \& Francis; 2011 Apr 19.

[57] Verdugo MÁ. El cambioeducativodesdeunaperspectiva de calidad de vida. Revista de educación. 2009 May;349(2):23-43.

[58] Doherty MT. Inclusion and deaf education: The perceptions and experiences of young deaf people in Northern Ireland and Sweden. International Journal of Inclusive Education. 2012 Aug 1;16(8):791-807.

[59] Hornby G. Inclusive special education: Development of a new theory for the education of children with special educational needs and disabilities. British Journal of Special Education. 2015 Sep;42(3):234-56.

[60] Schlumberger E, Narbona J, Manrique M. Non-verbal development of children with deafness with and without cochlear implants. Developmental medicine and child neurology. 2004 Sep;46(9):599-606.

[61] Guralnick MJ, Groom JM. The peer relations of mildly delayed and nonhandicapped preschool children in mainstreamed playgroups. Child Development. 1987 Dec 1:1556-72.

[62] Morningstar ME, Shogren KA, Lee H, Born K. Preliminary lessons about supporting participation and learning in inclusive classrooms. Research and Practice for Persons with Severe Disabilities. 2015 Sep;40(3):192-210.

[63] Bar-on M, Broughton D, Buttross S, Corrigan S, Gedissman A, De Rivas M, Rich M, Shifrin D, Brody M, Wilcox B, Hogan M. Children, adolescents, and television. Pediatrics. 2001 Feb 1;107(2):423-6.

[64] JAWAD, SHATHA Q., AMINA N. AL-THWAINI, and SALWA SH ABDUL-WAHID. "STUDY THE ASSOCIATION OF DAT1 GENE POLYMORPHISMS WITH ATTENTION DEFICIT HYPERACTIVITY DISORDER IN SAMPLE OF IRAQI PRIMARY SCHOOL CHILDREN." IMPACT: International Journal of Research in Engineering \& Technology (IMPACT: IJRET) 4.2 (2016) 25-36

[65] Singh, S. H. I. K. H. A., and S. H. I. P. R. A. Srivastava. "Nutrient intake and food adequacy of the school going children of Allahabad district." IMPACT: International Journal of Research in Applied, Natural and Social Sciences (IMPACT: IJRANSS) 4.3 (2016): 25-30. 
[66] Khalafallah, D. H., et al. "The impact of protocol of care for mothers of children with ventriculoperitoneal shunt on occurrence of postoperative complications." IMPACT: International Journal of Research in Applied, Natural and Social Sciences (IMPACT: IJRANSS) 5.2 (2017): 73-86

[67] UPRETI, RASHMI, and RITU SINGH. "A study of differences in adaptive behavioral skills of mentally challenged children with gender." International Journal of Humanities and Social Sciences (IJHSS) 5.2 (2016): 87-94.

[68] IBRAHIM, SHEHU SIDI, and I. IBRAHIM HADIZA. "CHILD LANGUAGE ACQUISITION IN RELATION TO REDUPLICATION: A CASE STUDY OF 6 (SIX) TWO-YEAR-OLD HAUSA CHILDREN." International Journal of Humanities and Social Sciences (IJHSS) 5.6 (2016): 113-124.

[69] SAINI, VARSHA, and BIMLA DHANDA. "RELATIONSHIP BETWEEN COMMUNICATION SKILLS AND DAILY LIVING SKILLS AMONG RURAL CHILDREN." International Journal of Humanities and Social Sciences (IJHSS) 6.1 (2017) 33-36 